\title{
Editorial EOT
}

\section{W. Puhl}

Published online: 29 June 2011

(C) EFORT 2011

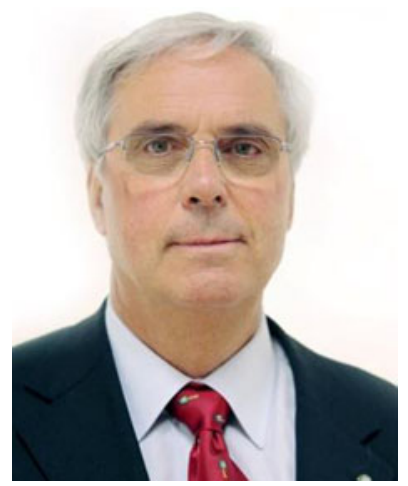

Dear EFORT members, members of specialty societies and readers of European Orthopaedics and Traumatology (EORT)

The EFORT journal, EORT, has finished its first year of existance.

Learning from the experiences of the first year, all members of EFORT and all national scientific orthopaedic societies were asked to nominate two editors each for the journal. We asked for experienced, active orthopaedic surgeons with a European vision to act as "liaison editors".

These editors will be the bridge between their National society and the EFORT journal. With this networking, we will have a better involvement of all member societies in the work and evolution of EFORT and we will be able to learn more about interesting topics discussed in orthopaedics all over Europe, with different needs in different regions.

We will also have a more direct route for all colleagues to the centre of EFORT and, hopefully, differently active colleagues will see the chance to give a picture of their society as well as the orthopaedic hospitals and different working teams of their country in basic and clinical research.

As we are working hard-together with a professional partner - to represent you all at the European political level in Brussels and Strasbourg, we will try to keep you informed about important facts, running discussions and decisions of the European legislation.

We will start with this in the next issue, to show you what interesting topics are on the agenda of the European parliament-topics which are deeply linked with daily orthopaedic work and the evolution of our profession in a changing world. 